\title{
Educational Research Applications
}

\section{An Investigation on the Student Performance in First Year Fun- damental Engineering Course, Engineering Statics}

\section{Md Mainul Islam*, Jayantha Ananda Epaarachchi}

School of Mechanical and Electrical Engineering, Faculty of Health, Engineering and Sciences, University of Southern Queensland, Toowoomba, Australia

"Corresponding author: Md Mainul Islam, School of Mechanical and Electrical Engineering, Faculty of Health, Engineering and Sciences, University of Southern Queensland, Toowoomba, Australia. Tel: +61746311338; Email: mainul.islam@usq.edu.au

Citation: Islam MM, Epaarachchi JA (2018) An Investigation on the Student Performance in First Year Fundamental Engineering Course, Engineering Statics. Educ Res Appl: ERCA-144. DOI: 10.29011/2575-7032/100044

Received Date: 22 February, 2018; Accepted Date: 09 March, 2018; Published Date: 16 March, 2018

\begin{abstract}
This paper details a quantitative investigation performed on the student performances in Engineering Statics, a fundamental engineering course. It is one of the highly numerical subjects that students encounter during early stage of their engineering programs and students are expected to complete large numbers of practice problems in order to learn the relevant theories. Historically, the success rate of the students enrolled in this subject was significantly below the average. The major cause for the higher failure rates was attributed to the lack of fundamental knowledge in mathematics. However, this study is intended to investigate the progressive performances of the students who satisfied the entry requirement and enrolled in the subject. The assessment marks were analysed against two categories such as delivery mode and the gender of the students to understand the critical causes of the outcome. Few statistical analyses were performed, and the results are presented in this paper.
\end{abstract}

\section{Introduction}

Engineering Statics course continues to be a mainstay of engineering education in many disciplines, forming an important prerequisite for many subsequent courses [1]. Almost every engineering student is required to take Engineering Statics as a core engineering course. This course is widely regarded by students as one of the most difficult courses, and many students fail because it covers abroad spectrum of fundamental engineering concepts. Understanding the differences in students' motivation, attitudes toward learning, and responses to different classroom environments and instructional practices helps instructor to meet student needs [2]. Since conceptual understanding is strongly tied to the ability to transfer newly acquired knowledge to other relevant engineering problem solving, itis a major goal of many engineering courses [3].

Prediction of student performance in the Engineering Statics is important because it helps not only the instructor to develop effective course curriculum and teaching strategies, but also facilitates students' increased understanding and development of effective learning strategies. Assessment is increasingly recognized as crucial to improve learning [4,5]. The Faculty of Health, Engineering and Sciences at the University of Southern
Queensland (USQ) has more than 2700 students (in all different years) enrolled in its three undergraduate engineering programs: the four-year Bachelor of Engineering Honours, the three-year Bachelor of Engineering Science and the two-year Associate Degree of Engineering. More than $75 \%$ of the students in these programs study off-campus through the distance education mode. Because of this reason the undergraduate student population is significantly diverse. For an example the age levels vary from 20 years to 60 years and students gained their high school education from all over the world. Further the students are working full/ part-time and married with children. This complex and diverse student population faces many socio-economic problems, which have not been included in any engineering education analysis. As a consequence the student performances are not following the standard average and associate patterns of usual on-campus student performances.

Engineering Statics course is being delivered in on-campus (ONC) and external (EXT) modes and the number of students enrolled in this course is significantly high as it is a fundamental first year course for all engineering programmes offered by the Faculty of Engineering and Surveying, USQ. Historically, the student performances of this subject are noticeably below the average with respect other Faculty courses and the student satisfaction was 


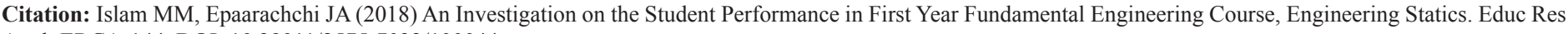
Appl: ERCA-144. DOI: 10.29011/2575-7032/100044

never met. The root causes for this deficiency were attributed to the lack of student knowledge on high school mathematics and physics as per observation by the Faculty. Since there is a significantly large external student population that undertakes this subject every year, it is reasonable to assume that the cause of students' unsatisfactory performances is not only the subject knowledge but also the socioeconomic problems. It is obvious that the quantitative analysis of the contribution of each cause towards the unsatisfactory performances of students is extremely prohibitive. However, due to these reasons the quantitative analysis of the student performances would not fall into the normal distribution. This paper details a basic analysis which was performed to investigate the patterns of student performances in Engineering Statics course quantitatively.

\section{Data and Analysis}

The final marks of the Engineering Statics course of Semester 1, 2007 were arbitrarily selected for the analysis as it represents the typical enrolment pattern. The total marks comprised with two assignments worth $40 \%$ and one restricted exam worth $60 \%$ of the total subject marks. The analysis was done in two separate categories, external and on-campus students. Also, each category was again subdivided into male and female groups. Preliminary investigation of student marks has shown that the distribution has some extremes and obviously does not fall into Normal distribution curve. However, there have been a large number of findings in the literature, indicating that the Normal distribution would be a suitable fit for many randomly varying variables such as fatigue life of a material. Historically Weibull distribution has been used for this type of extremely varying variables. There are numerous statistical analyses stating that the Weibull analysis and Normal distribution give similar fits to randomly varying variables if the sample population is significantly smaller.

As such, Normal and Weibull distributions were chosen for the quantitative analysis of the student performances. However Normal distribution does not provide any indication of the trends and the associated randomness of the data due to various unsolicited causes. For further details the reference [6] is recommended.

\section{Discussions}

As shown in Table 1, all categories of the students' marks are associated with a significant skewness. Female student marks show skewness in rightward (+ve skewness) while male student ones show leftward skewness, irrespective of the mode of enrolment. Further, mean of the female student marks are highest in their respective categories. Fundamentally, student marks distribution does not fall into a symmetric "Normal" distribution as anticipated.

\begin{tabular}{|c|c|c|c|c|}
\hline \multirow{2}{*}{ Student Category } & \multirow{2}{*}{ Skewness } & \multicolumn{2}{|c|}{ Weibull Distribution } & \multicolumn{2}{|c|}{ Normal Distribution } \\
\cline { 3 - 5 } & & Shape & Scale & Mean \\
\hline All EXT Students & -0.13 & 7.085 & 155.5 & 45.64 \\
\hline Male EXT Students & -0.26 & 7.614 & 154.8 & 45.42 \\
\hline Female EXT Students & 0.08 & 5.997 & 159.7 & 48.12 \\
\hline All ONC Students & -0.20 & 7.104 & 161.4 & 51.21 \\
\hline Male ONC Students & -0.21 & 7.058 & 161.4 & 51.19 \\
\hline Female ONC Students & 0.13 & 7.694 & 161.6 & 24.28 \\
\hline
\end{tabular}

Table 1: Basic statistics of student marks. 
Citation: Islam MM, Epaarachchi JA (2018) An Investigation on the Student Performance in First Year Fundamental Engineering Course, Engineering Statics. Educ Res Appl: ERCA-144. DOI: 10.29011/2575-7032/100044

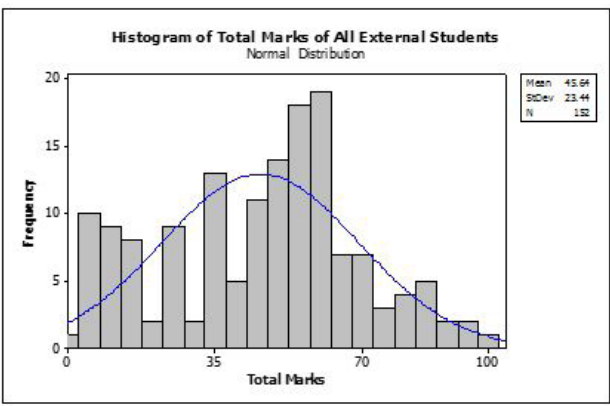

Figure 1: Histogram of total marks of all EXT students with fitted Normal curve.

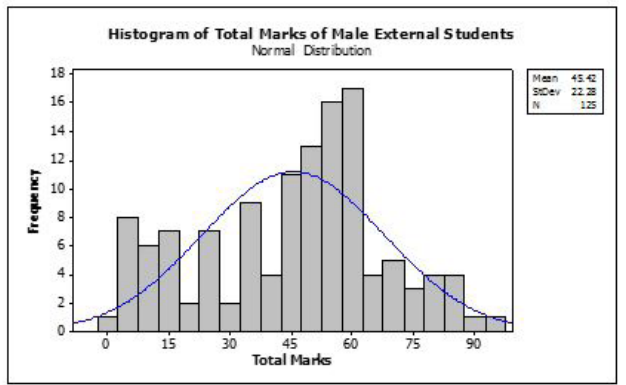

Figure 3: Histogram of total marks of male EXT students with fitted Normal curve

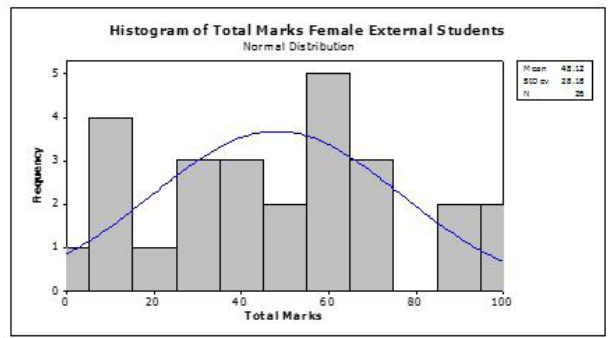

Figure 5: Histogram of total marks of female EXT students with fitted Normal curve.

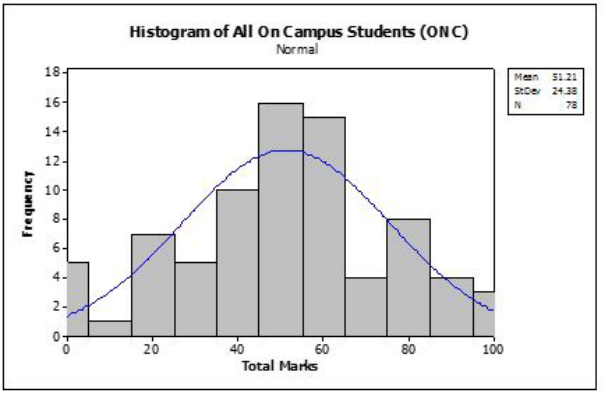

Figure 7: Histogram of total marks of all ONC students with fitted Normal curve.

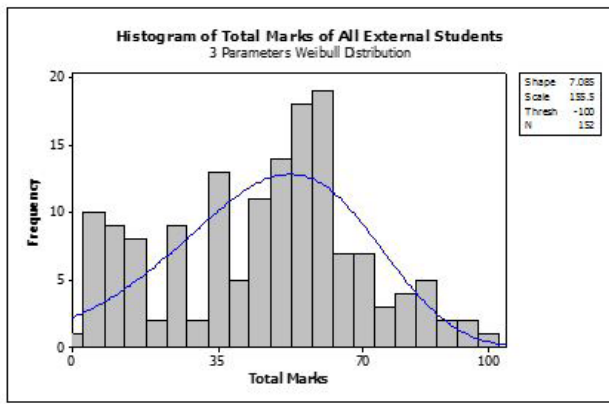

Figure 2: Histogram of total marks of all EXT students with fitte 3 parameter Weibull curve.

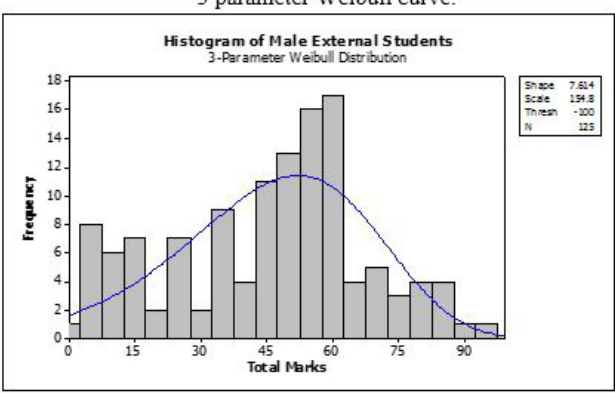

Figure 4: Histogram of total marks of male EXT students with fitted 3 parameter Weibull curve

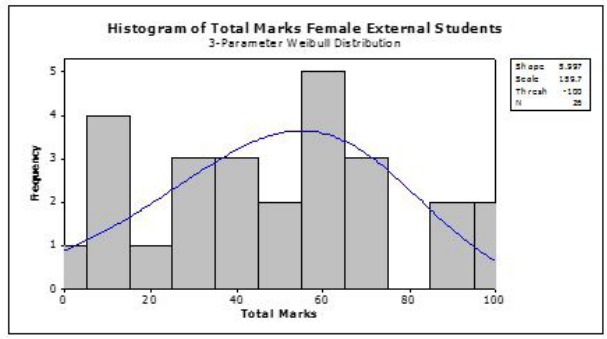

Figure 6: Histogram of total marks of female EXT students with fitted 3 varameter Weibull curve.

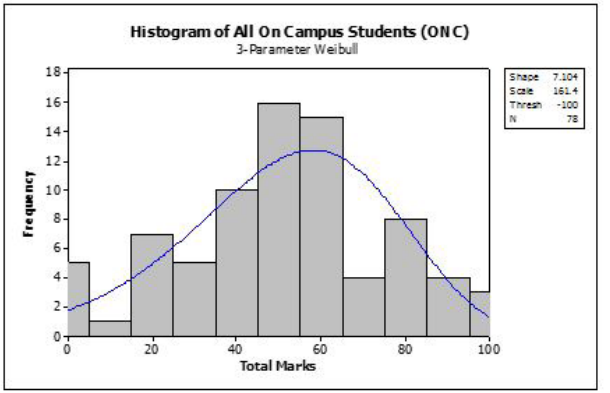

Figure 8: Histogram of total marks of all ONC students with fitted 3 parameter Weibull curve. 


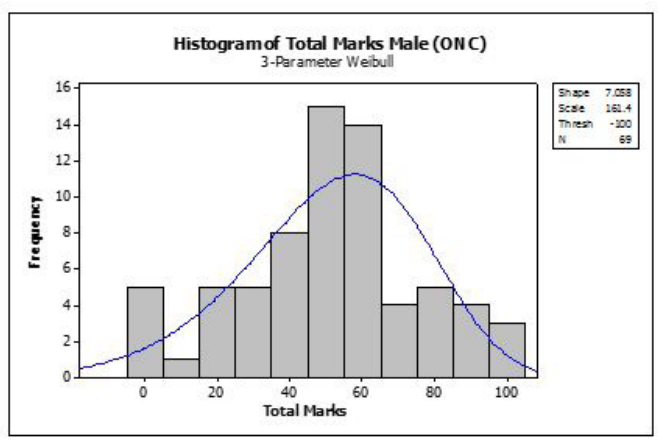

Figure 9: Histogram of total marks of Male ONC students with fitted Normal curve.

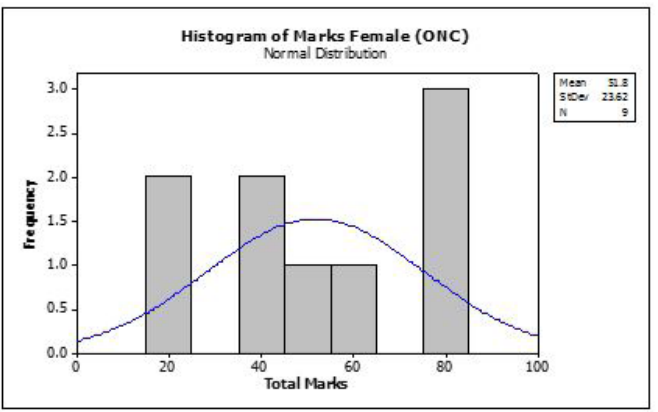

Figure 11: Histogram of total marks of female ONC students with fitted Normal curve.

As illustrated in Figures 1 and 2, three-parameter Weibull distribution has captured sufficiently the asymmetry of the mark distribution. The higher shape parameter, 7.085 (Table 1) indicates that the total mark will be increased with the time (or with the increased number of events). Interestingly the male students mark distribution follows the same trend (Figures 3 and 4) whilst female students mark distribution approaching a close fit to Normal distribution (Figures 5 and 6). This observation indicates that the male population is under maximum influence of identified and unidentified causes of poor performances.

Overall on-campus students mark distribution follows a similar trend to those external students mark distribution (Figures 7 and 8). However, the Normal distribution has a significantly close fit to the student mark distribution as shown in Figures 7, 9 and 11. This indicates the less influence in ONC students from the identified and unidentified causes of poor performances as anticipated. Further as illustrated in Figures 8, 10 and 12, the Weibull distribution captured the skewness associated in the mark distribution.

\section{Remarks and Questions for Further Discussion}

A preliminary statistical analysis has been performed on

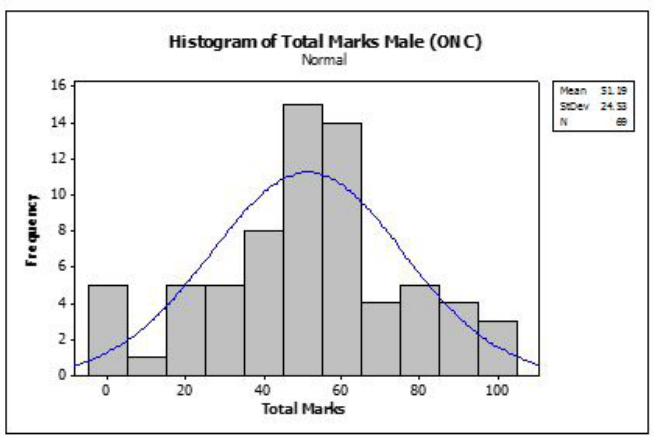

Figure 10: Histogram of total marks of male ONC students with fitted 3 parameter Weibull curve.

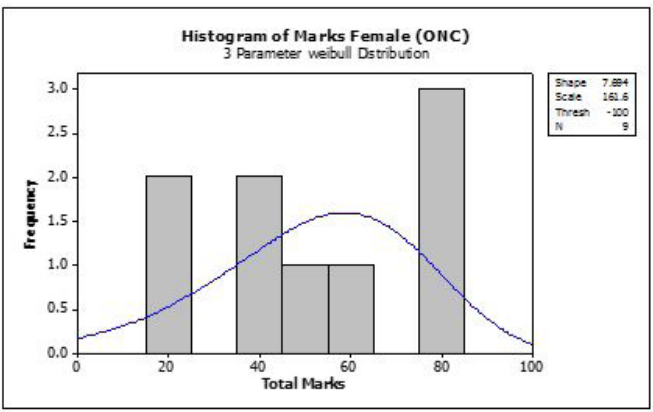

Figure 12: Histogram of total marks of all $\mathrm{ONC}$ students with fitted 3 parameter Weibull curve.

the students' total marks of a fundamental engineering course Engineering Statics, in order to identify the reflection of identified and unidentified causes of poor performances of students in this subject. As anticipated the randomness of mark distribution was captured by three-parameter Weibull distribution function. However, Normal distribution curve also has shown a closer fit. The indication from the analysis supports the assumption of the influences of socio-economic problems on the external student performances. But these conclusions are not conclusive, and more analyses are warranted for better understanding and further development of course deliveries. Now, the key questions for discussions are:

1. What should be the suitable approach to identify all possible causes of poor performance of the students?

2. How can we formulate the causes in a systematic way?

3. What should be our best strategies and practices to improve the student performance?

\section{References}

1. Dollar A, Steif PS (2008) An interactive, cognitively informed, webbased statics course. International Journal of Engineering Education 24: 1229-1241. 
Citation: Islam MM, Epaarachchi JA (2018) An Investigation on the Student Performance in First Year Fundamental Engineering Course, Engineering Statics. Educ Res Appl: ERCA-144. DOI: 10.29011/2575-7032/100044

2. Ribeiro LRC, Mizukami MGN (2005) Problem-based learning a student evaluation of an implementation in postgraduate engineering education. European Journal of Engineering Education 30: 137-149.

3. Coller BD (2008) An experiment in hands-on learning in engineering mechanics: statics. International Journal of Engineering Education 24: 545-557.

4. Steif PS, Hansen M (2006) Comparisons between performances in a statics concept inventory and course examinations. International Journal of Engineering Education 22: 1070-1076.
5. Fang N, Lu J (2010) A decision tree approach to predictive modeling of student performance in engineering dynamics. International Journal of Engineering Education 26: 87-95.

6. Andrew VM (1994) Statistics in engineering ( $1{ }^{\text {st }}$ ed.). Chapman \& Hall, London. 